group may be an issue, demonstrating that smokers are less likely to participate in lung cancer screening programmes than ex-smokers. ${ }^{18}$ Patel et $a l^{3}$ reported on the acceptance of annual CT scans, sputum cytometry and bronchoscopy surveillance in smokers and ex-smokers with mild to moderate chronic obstructive pulmonary disease (COPD) who had already consented to take part in the LungSEARCH trial. Although the majority of participants found the interventions acceptable, there was evidence of doubt about the value of early detection, particularly in older patients. They also found evidence to support the hypothesis that worry is a factor that deters people from participating in screening. Such considerations clearly need to be built in to costeffectiveness analyses of any national screening programme.

While it is vital we continue to push for effective screening programmes, those that use current technology are likely to be of limited benefit, costly and not likely to be implemented in the near future, at least in the UK. Strenuous efforts are also needed to find better screening methods that can eventually supersede CT scanning. We simply cannot wait and have to trial-and carefully evaluate- - a variety of approaches to promote earlier diagnosis in patients who already have symptoms of lung cancer.
Competing interests MDP is a co-author on the paper by Simon et al, though his contribution was limited to advice on some elements of the text and the conclusions rather than the design or analysis of the study. He is also a participant in the LungSEARCH trial which is the subject of the paper by Patel et al, though he is not a co-author and has not been directly involved in this sub-study or the preparation of the paper. He is the secondary care lead for the NAEDI programme.

Provenance and peer review Commissioned; internally peer reviewed.

Published Online First 17 March 2012

Thorax 2012;67:379-380

doi:10.1136/thoraxjnl-2011-201449

\section{REFERENCES}

1. Simon A, Juszczyk D, Smyth N, et al. Knowledge of lung cancer symptoms and risk factors in the UK: development of a measure and results from a population-based survey. Thorax 2012;67:426-32.

2. Athey V, Suckling R, Tod A, et al. Early diagnosis of lung cancer: evaluation of a community-based social marketing intervention. Thorax 2012;67:412-7.

3. Patel D, Akporobaro A, Chinyanganya N, et al Attitudes to participation in a lung cancer screening trial: a qualitative study. Thorax 2012;67:418-25.

4. Coleman MP, Forman D, Bryant $\mathrm{H}$, et al. Cancer survival in Australia, Canada, Denmark, Norway, Sweden, and the UK, 1995-2007 (the International Cancer Benchmarking Partnership): an analysis of population-based cancer registry data. Lancet 2011;377:127-38

5. Abdel-Rahman $\mathbf{M}$, Stockton D, Rachet B, et al. What if cancer survival in Britain were the same as in Europe: how many deaths are avoidable? Br J Cancer 2009;101(Suppl 2):S115-24.

6. NHS Information Centre. National Lung Cancer Audit. 2010 Annual report. http://www.ic.nhs.uk/ webfiles/Services/NCASP/audits\%20and\%20reports/
NHSIC_National_Lung_Cancer_Audit_2010_V1.0.pdf (accessed 13 Dec 2011).

7. The National Lung Screening Trial Research Team. Reduced lung-cancer mortality with low-dose computed tomographic screening. $N$ Engl J Med 2011;365:395-409

8. Imperatori A, Harrison $\mathrm{R}$, Leitch $\mathrm{DH}$, et al. Lung cancer in Teesside (UK) and in Varese (Italy): a comparison of management and survival. Thorax 2006;61:232-9.

9. Holmberg L, Sandin F, Bray F, et al. National comparisons of lung cancer survival in England, Norway and Sweden 2001-2004: differences occur early in follow-up. Thorax 2010;65:436-41.

10. National Cancer Intelligence Network. Routes to Diagnosis. NCIN report available via: http://www. ncin.org.uk (accessed 13 Dec 2011).

11. Corner J, Hopkinson J, Fitzsimmons D, et al. Is late diagnosis of lung cancer inevitable? Interview study of patients' recollections of symptoms before diagnosis. Thorax 2005;60:314-19.

12. Jensen AR, Mainz J, Overgaard J. Impact of delay on diagnosis and treatment of primary lung cancer. Acta Oncol 2002:41:147-52.

13. Cancer Research UK: About NAEDI. http://info. cancerresearchuk.org/spotcancerearly/naedi/ AboutNAEDI/ (accessed 13 Dec 2011).

14. Gleeson FV. Screening for lung cancer with spiral CT is not justified. Nat Clin Pract Oncol 2007;4:442-3.

15. Henschke C. CT screening for lung cancer is justified. Nat Clin Pract Oncol 2007:4:440-1.

16. Spiro SG. Screening for lung cancer: yet another problem. Thorax 2007;62:105-6.

17. Office for National Statistics. General Lifestyles Survey (Data for 2009). http://www.ons.gov.uk/ons/ publications/re-reference-tables.html?edition $=\mathrm{tcm} \%$ 3A77-198839 (accessed 16 Dec 2011).

18. Silvestri GA, Nietert PJ, Zoller J, et al. Attitudes towards screening for lung cancer amongst smokers and their non-smoking counterparts. Thorax 2007;62:126-30.

\title{
Airway disease and emphysema on CT: not just phenotypes of lung pathology
}

\section{Peter D Paré, ${ }^{1}$ Pat G Camp}

In this issue of the journal, Martinez et al ${ }^{1}$ examined the relationships between quantitative CT (OCT) parameters of emphy-

\footnotetext{
1Department of Medicine, Camp Department of Physical Therapy, University of British Columbia, James Hogg Research Centre, St. Paul's Hospital, Vancouver, Canada; ${ }^{2}$ Department of Physical Therapy, University of British Columbia, James Hogg Research Centre, St Paul's Hospital, Vancouver, Canada

Correspondence to Dr Peter D Paré, Department of Medicine, Camp Department of Physical Therapy, James Hogg Research Center, St. Paul's Hospital, University of British Columbia, 1081 Burrard Street, Vancouver V6Z 1Y6, Canada; peter.pare@hli.ubc.ca
}

sema, airway wall remodelling and airway narrowing and composite clinical and physiological indices of chronic obstructive pulmonary disease (COPD), the BODE index ${ }^{2}$ and the St George's Respiratory Questionnaire (SGRQ). ${ }^{3}$ BODE stands for Body mass index (BMI), airflow Obstruction, Dyspnoea and Exercise capacity.

Not surprisingly, these OCT estimates of pathological changes were related to measures of clinical impact. More interestingly, the authors found that there were differences in the strength of the associations between measures of emphysema and airway disease and the composite indices. Measures of emphysema were more closely related with the BODE index while the airway wall abnormalities were better predictors of the SGRO.

While it has long been recognised that there is a spectrum of changes in the airways and parenchyma in $\mathrm{COPD},{ }^{4}$ the separation of the airway predominant phenotype from the parenchymal predominant phenotype was largely limited to the autopsy room until the advent of CT. CT has confirmed that some patients have airflow obstruction with little emphysema while others have predominant emphysema with little airway disease. Such individuals form the extremes while the majority of patients have various combinations of airway disease and emphysema. ${ }^{5}$ In addition, there is evidence that the predominant pattern is to some extent familial ${ }^{6}$ and is associated with different rates of decline of lung function. ${ }^{7}$ The presence of airway disease and emphysema on CT can be assessed qualitatively or quantitatively. The power 
of the quantitative indices, as used in the present study, is that they are completely reproducible provided that similar scanners, imaging parameters and software are used. The hope is that the separate mechanisms that lead to these pathological changes in COPD can be individually targeted by specific therapy and followed non-invasively with repeat imaging.

Since CT allows a measure of anatomic derangement, its validation has largely been by comparison with pathological estimates of emphysema and airway disease. Many studies have shown that CT provides an accurate estimate of the extent and severity of emphysema, ${ }^{8-11}$ although only a few have compared CT measures of airway lumen narrowing and wall remodelling with pathological changes. ${ }^{12}$

More recently, there have been a number of studies in which quantitative estimates of CT phenotypes have been compared with clinical phenotypes, measures of lung function and symptoms. ${ }^{13-19}$ The reasoning is that, in the absence of a structural gold standard, lung function and symptoms can act as surrogates for test validity. If CT can accurately assess anatomic derangement of lung structure and if structural damage correlates with lung function and symptoms, then there should be good relationships between the CT measures and these clinical features. In general, the results of these studies have been reasonably robust, supporting the idea that CT can be used to grade the clinical as well as the pathological severity of COPD. Martinez et al ${ }^{1}$ have added a new dimension to the puzzle. By comparing the CT measures of emphysema and airway disease with the SGRO and the BODE index they have found that specific "pathological' features are more closely related to certain combinations of clinical features.

To understand their results more fully we need to examine what goes into determining the SGRO and BODE scores. The SGRO (http://www.healthstatus.sgul. ac.uk/sgrq-downloads/sgrq-c-downloads) is a 50-item questionnaire that assesses respiratory symptoms, physical activity and psychosocial well-being. In addition to providing a total score, scores for the three domains can be determined independently. The SGRO correlates significantly with other measures of disease activity such as cough, dyspnoea, 6-minute walk distance (6MWD) and forced expiratory volume in one second (FEV1) as well as measures of general health status such as the SF36. The BODE index is more complex and was developed to predict risk of death in COPD. It is derived from the combination of a measure of nutritional status (BMI), the degree of airflow obstruction (FEV1 \% predicted), the severity of dyspnoea (Modified Medical Research Council (MMRC) dyspnoea scale), and the 6MWD.

Fortunately Martinez et $a l^{1}{ }^{1}$ in their supplementary data, also report the relationship between OCT measures and the components of the SGRQ and BODE index so that we can appreciate which were the primary drivers for the relationships. Interestingly, all the measures which contribute to the BODE index were significantly related (by univariate Spearman correlation) to both emphysema score and Pi10 as a marker of airway remodelling. However, the relationship between emphysema and FEV1\% predicted was the strongest of the four components of the BODE $(\mathrm{r}=-0.54, \mathrm{p}<0.001)$. Nakano et at compared OCT measures of emphysema and airway wall remodelling with FEV1 \% predicted and also found that there was a substantially better correlation with emphysema than with airway wall parameters. CT emphysema was also significantly related to BMI with lower BMI in subjects who had worse emphysema $(r=-0.27, p<0.001)$. It is well known that for equal degrees of airflow obstruction, individuals who have worse emphysema have lower BMI (or persons with low BMI have worse emphysema-the direction of this relationship is unclear). ${ }^{20}$ Thus the stronger relationship of BODE with QCT emphysema could be driven by these two factors. However, the emphysema score was also related to the other two components of the BODE, the 6MWD and the MMRC dyspnoea index. Diaz et al ${ }^{18}$ have examined the relationship between 6MWD and QCT-defined measures of emphysema and airway disease and found that emphysema was better correlated with the 6MWD than airway remodelling parameters. In the present study, the strength of the association, as assessed by $r$ values was slightly stronger for Pi10 $(\mathrm{r}=-0.33, \mathrm{p}<0.001)$ than for emphysema $(\mathrm{r}=-0.24, \mathrm{p}<0.001)$. Interestingly, the factor that may contribute to the weaker relationship between the BODE index and airway scores is the completely opposite, but significant, relationship between BMI and airway remodelling (Pi10). Individuals who have thicker airways have significantly greater $\mathrm{BMI}(\mathrm{r}=0.17, \mathrm{p}<0.001)$. This positive relationship between measures of airway wall remodelling and BMI (or body weight) has been previously reported by Lee et $a l^{19}$ and Camp et al, ${ }^{21}$ but its cause and significance is unknown.
More surprising to us was the closer relationship of airway wall parameters to respiratory health status as measured by the SGRQ. Why would respiratory health status measures be more closely related to airway pathology than emphysema? Previous studies have reported an association of measures of altered airway dimensions with symptoms such as cough, sputum, wheeze and dyspnoea. For example, Lee et $a l^{19}$ reported that CTmeasured wall area and wall area per cent correlated with dyspnoea as measured with the MMRC, whereas the CT measure of emphysema did not. In supplementary table 2 Martinez et al ${ }^{1}$ used multivariate analysis to determine the independent contribution of the three SGRQ domains to the relationships with airway remodelling and emphysema. All three domainssymptoms, impacts and activity-were significantly associated with airway wall remodelling (Pi10). On the other hand, quantitative emphysema was only associated with the activity score and unrelated to symptoms and impacts. It is understandable that the symptoms of cough, sputum and wheeze are more closely related to airway morphology than to emphysema. The relationship of emphysema to activity is also logical since dynamic hyperinflation during exercise is an expected consequence of the loss of lung recoil that is characteristic of emphysema. What is unclear is why the impacts domain, which measures psychosocial impacts of COPD (including questions on panic during symptoms, or feeling one is a burden to friends or family), relates to airway disease measures but not to emphysema. We are unaware of any study that has probed the relationships between phenotypes of COPD and psychosocial functioning, but if the relationship between the airway measurements and the SGRO impacts component can be confirmed, this could lead to an intriguing area of investigation.

It is especially impressive that airway measurements correlated so well with the SGRO since the airways that are assessed using high resolution CT are relatively large airways which are not the site of major airway resistance in COPD. The fact that large airway dimensions are related to respiratory health status as measured by the SGRQ supports the suggestion that airway wall remodelling in large airways is a reflection of generalised airway narrowing and/or obliteration as has been suggested by Nakano et al. ${ }^{12} \mathrm{McD}$ onough et al ${ }^{22}$ have recently shown that an early lesion in COPD is the loss of terminal bronchioles. Perhaps there is a relationship between this 
obliterative process in the smallest of the conducting airways and the inflammatory/ fibrotic process that thickens and narrows the larger airways that are visible on CT.

In summary, the results of Martinez et al ${ }^{1}$ raise important questions about the relationship between structural changes in the lung, abnormalities of lung function and respiratory related symptoms, physical activity and psychosocial impacts. It is somewhat paradoxical that the authors chose to compare more precise morphological features of COPD with composite measures of function and symptoms since the COPD community is striving to separate subphenotypes of COPD based on pathogenetic mechanisms and structural changes. However, by identifying the relationships between these CT features and the components of the composite scores, the authors have allowed us to more precisely determine their relationship to CT features and in so doing have raised important issues.

Contributors PDP and PGC contributed equally to this editorial.

\section{Competing interests None.}

Provenance and peer review Not commissioned; internally peer reviewed.

Thorax 2012;67:380-382.

doi:10.1136/thoraxjnl-2012-201769

\section{REFERENCES}

1. Martinez C, Chen $\mathrm{Y}-\mathrm{H}$, Westgate PM, et al. Relationship between quantitative CT metrics andhealth status and BODE in chronic obstructive pulmonary disease. Thorax 2012:67;399-406.
2. Celli BR, Cote CG, Marin JM, et al. The body-mass index, airflow obstruction, dyspnea, and exercise capacity index in chronic obstructive pulmonary disease. N Engl J Med 2004;350:1005-12.

3. Jones PW, Quirk FH, Baveystock CM. The St. George's respiratory questionnaire. Respir Med 1991;85(Suppl B):25-31

4. Burrows B, Bloom JW, Traver GA, et al. The course and prognosis of different forms of chronic airways obstruction in a sample from the general population. N Engl J Med 1987;317:1309-14.

5. Nakano Y, Muro S, Sakai H, et al. Computed tomographic measurements of airway dimensions and emphysema in smokers. Correlation with lung function. Am J Respir Crit Care Med 2000;162:1102-8.

6. Patel BD, Coxson H0, Pillai SG, et al; International COPD Genetics Network. Airway wall thickening and emphysema show independent familial aggregation in chronic obstructive pulmonary disease. Am J Respir Crit Care Med 2008;178:500-5.

7. Yuan R, Hogg JC, Paré PD, et al. Prediction of the rate of decline in FEV(1) in smokers using quantitative Computed Tomography. Thorax 2009;64:944-9.

8. Bergin C, Müller N, Nichols DM, et al. The diagnosis of emphysema. A computed tomographicpathologic correlation. Am Rev Respir Dis 1986;133:541-6.

9. Bankier AA, De Maertelaer V, Keyzer $C$, et al. Pulmonary emphysema: subjective visual grading versus objective quantification with macroscopic morphometry and thin-section CT densitometry. Radiology 1999;211:851-8.

10. Gevenois PA, de Maertelaer V, De Vuyst P, et al Comparison of computed density and macroscopic morphometry in pulmonary emphysema. Am J Respir Crit Care Med 1995;152:653-7.

11. Kuwano K, Matsuba K, Ikeda T, et al. The diagnosis of mild emphysema. Correlation of computed tomography and pathology scores. Am Rev Respir Dis 1990;141:169-78

12. Nakano $\mathbf{Y}$, Wong JC, de Jong PA, et al. The prediction of small airway dimensions using computed tomography. Am J Respir Crit Care Med 2005;171:142-6.

13. Mets $\mathbf{O M}$, Murphy K, Zanen $\mathrm{P}$, et al. The relationship between lung function impairment and quantitative computed tomography in chronic obstructive pulmonary disease. Eur Radiol 2012;22:120-8.

14. Grydeland TB, Thorsen E, Dirksen A, et al. Quantitative CT measures of emphysema and airway wall thickness are related to $\mathrm{D}(\mathrm{L}) \mathrm{CO}$. Respir Med 2011;105:343-51.

15. Grydeland TB, Dirksen A, Coxson HO, et al. Quantitative computed tomography measures of emphysema and airway wall thickness are related to respiratory symptoms. Am J Respir Crit Care Med 2010;181:353-9.

16. Han MK, Bartholmai B, Liu LX, et al. Clinical significance of radiologic characterizations in COPD. COPD 2009;6:459-67.

17. Gietema HA, Müller NL, Fauerbach PV, et al; Evaluation of COPD Longitudinally to Identify Predictive Surrogate Endpoints (ECLIPSE) investigators. Quantifying the extent of emphysema: factors associated with radiologists' estimations and quantitative indices of emphysema severity using the ECLIPSE cohort. Acad Radiol 2011;18:661-71.

18. Diaz AA, Bartholmai B, San José Estépar R. Relationship of emphysema and airway disease assessed by CT to exercise capacity in COPD. Respir Med 2010:104:1145-51.

19. Lee YK, Oh YM, Lee JH, et al; KOLD Study Group. Quantitative assessment of emphysema, air trapping and airway thickening on computed tomography. Lung 2008;186:157-65.

20. Ogawa E, Nakano Y, Ohara T, et al. Body mass index in male patients with COPD: correlation with low attenuation areas on CT. Thorax 2009;64:20-5.

21. Camp PG, Coxson HO, Levy RD, et al. Sex differences in emphysema and airway disease in smokers. Chest 2009;136:1480-8.

22. McDonough JE, Yuan R, Suzuki M, et al. Smallairway obstruction and emphysema in chronic obstructive pulmonary disease. $N$ Engl J Med 2011;365:1567-75

\section{Hot off the breath: 'I've a cost for'-the 64 million dollar question}

\section{Andrew Bush, ${ }^{1}$ Nicholas J Simmonds ${ }^{2}$}

On 12 January 2012, the US Food and Drug Administration (FDA) licensed Ivacaftor for use in patients with cystic

\footnotetext{
'Department of Paediatric Respiratory Medicine, Imperial College and Royal Brompton Harefield NHS Foundation Trust, Sydney Street, London, UK; ${ }^{2}$ Department of Cystic Fibrosis, Imperial College and Royal Brompton Harefield NHS Foundation Trust, Sydney Street, London, UK

Correspondence to Professor Andrew Bush, Department of Paediatric Respiratory Medicine, Imperial College and Royal Brompton Harefield NHS Foundation Trust, Sydney Street, London SW3 6NP, UK; a.bush@imperial.ac.uk
}

fibrosis (CF) aged 6 years and over, who carry at least one copy of the class 111 mutation G551D. The cost per patient year in the USA will be a staggering US \$294 000. Given that patients with G551D account for around $5 \%$ of the total CF population, and assuming that the price will be similar in the UK, if these patients are to receive this medication, there will be a hole in someone's budget to the extent of $£ 60$ million, because the one absolute certainty is that the government will not be making any more money available to cover the costs of this medication. To give context-the total national budget for $\mathrm{CF}$ care is of the order of $£ 110$ million. This is certainly a 'wow-factor' price; is it a wowfactor medication? What are the ethics of having a $50 \%$ hike in the CF drug budget driven by $5 \%$ of the population? And where do we go from here?

The history of CF treatment has been by any standards a major success story. Median survival has risen from less than a year in 1938 to a predicted value for current newborns of around 50 years. ${ }^{1}$ This has arisen from advances in the multidisciplinary treatment of the condition, and latterly with earlier diagnosis through newborn screening. Although standard treatment is increasingly successful, it leads to considerable burdens on the patients and their families, and largely comprises firefighting, namely treating the downstream consequences of the CF transmembrane regulator (CFTR) gene dysfunction, such as airway infection. However, Ivacaftor represents a stupendous paradigm shift, the 